Case Report

\title{
Sight threatening to life threatening parainfectious optic neuritis
}

\author{
Sowmya V. ${ }^{1}$, Vijna B. Kamath ${ }^{2}$, Nelly E. P. Nazareth ${ }^{3}$ \& F. E. A. Rodrigues ${ }^{4}$ \\ Medical College, Kankanady, Mangalore. \\ Correspondence \\ Sowmya V. \\ Senior Resident, Department of Ophthalmology, \\ Father M uller M edical College, Kankanady, Mangalore - 575002. \\ E-mail: drsowmyav@yahoo.com
}

${ }^{1}$ Senior Resident, ${ }^{2}$ Post graduate, ${ }^{3}$ Associate Professor, ${ }^{4}$ Professor, Department of Ophthalmology, Father Muller

\begin{abstract}
Optic neuritis is uncommon in children and is often bilateral unlike that in adults. It is often associated with systemic diseases like mumps, measles, chicken pox, pertussis, viral encephalitis and also following immunization. We report a series of 3 consecutive paediatric cases of bilateral optic neuritis which presented to us over a period of 6 months and were followed up for 1 year. Two patients responded to steroids with a normal ophthalmic and MRI examination at the end of one year. One patient expired following development of Acute Disseminated Encephalomyelitis.
\end{abstract}

Keywords: optic neuritis, para- infectious diseases, acute disseminated encephalomyelitis

\section{Introduction}

Optic neuritis is uncommon in children and is often bilateral unlike that in adults ${ }^{1}$. It can occur following systemic diseases like mumps, measles, chicken pox, pertussis and viral encephalitis'. Immunization has also been associated with episodes of optic neuritis3. Aim of our study is to describe the diverse manifestations of para infectious diseases in children.

\section{Material and Methods}

Series of three consecutive paediatric cases of bilateral optic neuritis which presented to us over a period of six months from January 2013 to June 2013 were studied and followed up for one year. All cases had sudden onset severe visual loss. General and neurological examination was normal at presentation. Of the three children, two were females and one male. The first two patients were a six and seven year old girls respectively who had an episode of chicken pox two weeks prior to the onset of visual loss. The

\begin{tabular}{|c|}
\hline Access this article online \\
\hline Quick Response Code
\end{tabular}

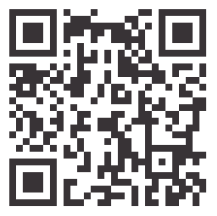

third patient was a three year old boy who had an episode of mumps ten days before the onset of visual loss. The visual acuities ranged between counting fingers to perception of light. Colour vision was impaired in first 2 patients and could not be assessed in the 3rd patient. Pupils were ill sustained to light. Ophthalmoscopy revealed bilateral hyperaemic and swollen discs in all 3 cases suggestive of post para-infectious bilateral optic neuritis (Figure 1). Paediatric opinion was taken in all three cases. All the three cases were started on Intravenous methylprednisolone $30 \mathrm{mg} / \mathrm{kg}$ stat $x 3$ days followed by a tapering course of oral prednisolone.

Clinical response to the treatment was monitored on the basis of visual acuity, disc changes and general and neurological status. At the end of first week disc oedema persisted in all the 3 cases. However the visual acuity improved in the first two children (Table 2). In case of the third child the general condition deteriorated. M RI scan of the boy (Figure 2) revealed large, patchy areas of subcortical and deep white matter hyperintensity in the bilateral corona radiata consistent with ADEM (Acute Disseminated Encephalomyeltis). CSF Analysis revealed lymphocytic pleocytosis. General and neurological status worsened and the boy succumbed to the neurological disease on the fifth day. The two other cases were followed up to a period of one year with visual acuity and funduscopy being performed at the end of two, six and twelve months. M RI scan was done at the end of the year in 
both the children. Visual acuity had improved to $6 / 6$ at the end of two months itself in the first child and remained so at the end of one year of follow up. Visual acuity in the second child was $6 / 6$ (OD) and 6/9(OS) at the end of two months and remained the same at the end of one year of follow up. Funduscopy revealed a normal optic disc in both the cases and a normal M RI at the end of one year of follow up (table 3).

\section{Conclusion}

Optic neuritis in children is usually bilateral and associated with optic disc swelling. Often occurs 1 to 2 weeks after viral or bacterial infection or vaccination ${ }^{3,4}$. The initial vision is usually very poor but the visual recovery is usually good. Associated ADEM (acute disseminated encephalomyelitis), a neurologic disorder characterized by inflammation and damage to the myelin sheath of the brain and spinal cord, likely from a transient autoimmune response is common in children. $70 \%$ of patients report a precipitating event, e.g. viral or bacterial infections or vaccination. It has an abrupt onset and a monophasic

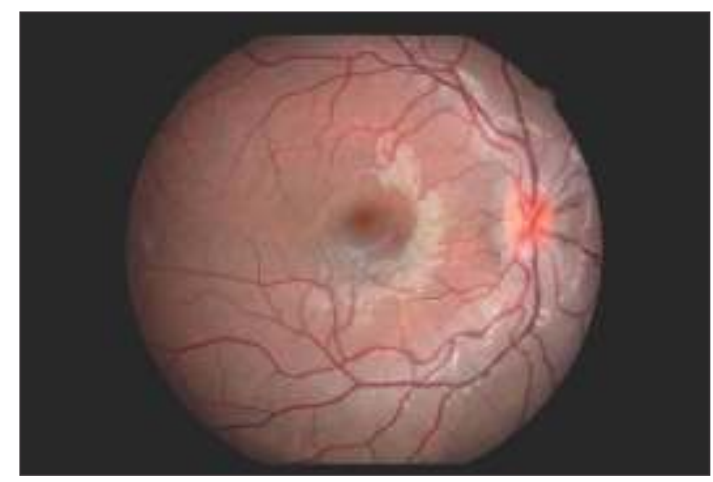

Figure 1 : Fundus photograph of the first patient at presentation showing bilateral disc edema course presenting with headache, seizures, and altered mental status, bilateral optic neuritis and visual field defects $^{6}$. M ortality rate of up to $20 \%$ has been reported ${ }^{7}$. Optic neuritis must be considered in the differential diagnosis of bilateral sub-acute visual loss, especially occurring 1 to 2 weeks after a previous viral infection in children. General condition should be monitored closely to prevent Para infection related morbidity and mortality.

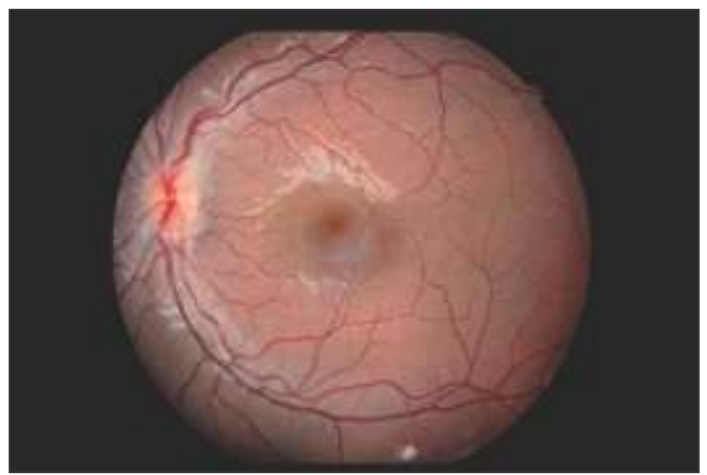

Figure 2 : M RI brain of the boy. Red arrow showing large, patchy areas of subcortical and deep white matter and hyperintensity in the bilateral corona radiata consistent with ADEM (Acute Disseminated Encephalomyeltis) in a T2 weighted image.

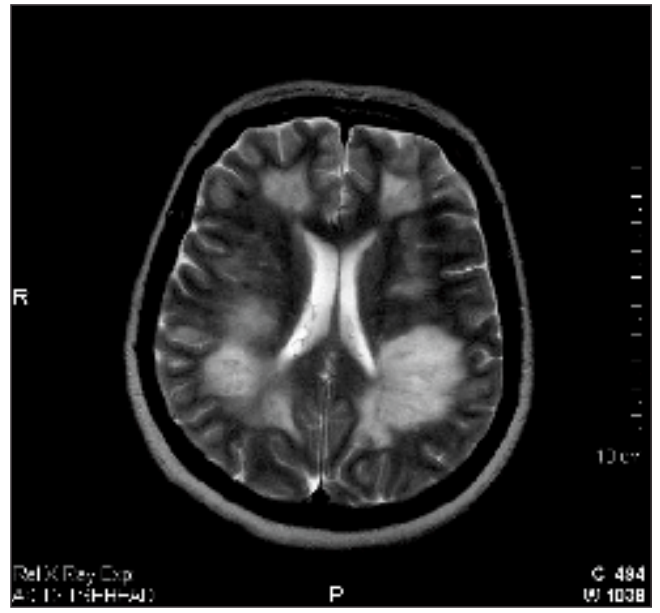

Table 1 : Clinical characteristics of the patients

\begin{tabular}{|l|c|c|c|c|c|c|}
\hline $\begin{array}{l}\text { Patient } \\
\text { No }\end{array}$ & Age & Sex & Initial visual acuity & $\begin{array}{c}\text { Initial appearance } \\
\text { of the disc }\end{array}$ & $\begin{array}{c}\text { Preceding viral } \\
\text { illness }\end{array}$ & $\begin{array}{c}\text { Duration between viral } \\
\text { illness and optic neuritis }\end{array}$ \\
\hline 1. & 6 & F & $\begin{array}{c}(\mathrm{OD}): \text { CF } 1 / 2 \mathrm{~m} \\
(\mathrm{OS}): 6 / 60\end{array}$ & B/L disc edema & Chicken pox & 2 weeks \\
\hline 2. & 7 & F & $\begin{array}{c}(\mathrm{OD}): \mathrm{HM} \\
(\mathrm{OS}): \text { CF } 2 \mathrm{~m}\end{array}$ & B/L disc edema & Chicken pox & 2 weeks \\
\hline 3. & 3 & M & $\begin{array}{c}(\mathrm{OD}): \mathrm{PL}+ \\
(\mathrm{OS}): \mathrm{HM}\end{array}$ & B/L disc edema & M umps & 10 days \\
\hline
\end{tabular}


Table 2 : Clinical response at the end of 1st week

\begin{tabular}{|l|l|l|l|}
\hline Pt. No & BCVA at the end of $1^{\text {st }}$ week & Disc changes at the end of $1^{\text {st }}$ week & General and neurological status \\
\hline 1. & $(\mathrm{OD}): 6 / 36(\mathrm{OS}): 6 / 24$ & $\mathrm{~B} / \mathrm{L}$ disc edema & normal \\
\hline 2. & $(\mathrm{OD}): 6 / 60(\mathrm{OS}): 6 / 24$ & $\mathrm{~B} / \mathrm{L}$ disc edema & normal \\
\hline 3. & Could not be assessed & B/L disc edema & $\begin{array}{l}\text { Altered mental status and } \\
\text { deterioration of general condition } \\
\text { on the } 2^{\text {nd }} \text { day }\end{array}$ \\
\hline
\end{tabular}

Table 3 : Follow up at the end of one year

\begin{tabular}{|l|l|c|c|c|c|}
\hline Pt. No & BCVA at the end & BCVA at the end & BCVA at the end & Optic disc at the end & M RI at the end \\
\hline & of 2 months & of 6 months & of 1 year & of 1 year & of 1 year \\
\hline 1. & (OD) $: 6 / 6(O S) 6 / 6$ & (OD) $: 6 / 6($ OS) $6 / 6$ & (OD) $: 6 / 6(O S) 6 / 6$ & NORMAL & NORM AL \\
\hline 2. & (OD) $: 6 / 6(\mathrm{OS}) 6 / 9$ & (OD) $: 6 / 6(\mathrm{OS}) 6 / 9$ & (OD) $: 6 / 6(\mathrm{OS}) 6 / 9$ & NORMAL & NORM AL \\
\hline
\end{tabular}

\section{References}

1. Kennedy C, Carrol F. optic neuritis in children. Arch ophthalmol 1960, 63: 747-75

2. Farris B, Pickard D. Bilateral postinfectious optic neuritis and intravenous steroid therapy in children.Ophthalmology, 1990, 97:33945

3. Riikonen $\mathrm{R}$. The role of infection and vaccination in the genesis of optic neuritis and multiple sclerosis in children. Acta Neurol (Scand) 1989;80:425-31

4. Badr M, Al-Smayer S. Bilateral optic neuritis in a 10-year-old girl. Middle East Afr J Ophthalmol 2007;14:76-8

5. Sriram S, Steinman L : Post-infectious and post-vaccinial encephalomyelitis. Neurol Clin 1984; 2:341-53

6. Murthy J M. Acute disseminated encephalomyelitis. Neurol India 2002:50:238

7. Miller HG, Stanton JB, Gibbons JL: Parainfectious encephalomyelitis and related syndromes. QJM 1956; 25:427-505 